\title{
Continuous positive arrway pressure does not improve lung function after cardiac surgery
}

\section{[La ventilation en pression positive continue n'améliore pas la fonction pulmonaire} après la cardiochirurgie]

Ece Altmay MD, * Pelin Karaca MD, * Nurgül Yurtseven MD, * Vedat Özkul MD, * Tamer Aksoy MD, * Azmi Özler MD, $†$ Sevim Canik MD*

Purpose: Despite the well-documented impairment of pulmonary function after cardiopulmonary bypass, effective precautions and ideal management strategies for this problem are still under debate. This study aimed to evaluate the effects of continuous positive airway pressure (CPAP) applied during cardiopulmonary bypass on respiratory and hemodynamic variables.

Methods: In this randomized, prospective, controlled trial, 120 male patients, aged 45 to $70 \mathrm{yr}$ undergoing first-time elective bypass surgery, were randomly assigned to receive either $10 \mathrm{~cm}$ $\mathrm{H}_{2} \mathrm{O}$ of CPAP (Group I; $n=60$ ) during cardiopulmonary bypass, or serve as control (Group II; $n=60$ ), where the patient's lungs were vented to atmosphere during the bypass period.

Results: Alveolar-arterial oxygen partial pressure difference and shunt fraction were significantly higher in the control group compared with the CPAP group after cardiopulmonary bypass $\left(T_{2}\right)$ and after closure of sternum $\left(T_{3}\right),(P<0.05)$. No differences between groups with respect to hemodynamic variables were observed at any time. Postoperative pulmonary function variables were lower in both groups compared to baseline values.

Conclusions: Continuous positive airway pressure administered during cardiopulmonary bypass decreased shunt fraction and alveolar-arterial oxygen partial pressure difference during surgery, but had no sustained effect on either variable postoperatively. We conclude that, in patients with normal preoperative pulmonary function, application of $10 \mathrm{~cm} \mathrm{H}_{2} \mathrm{O}$ CPAP does not improve lung function after cardiac surgery.
Objectif: Malgré les connaissances acquises sur l'atteinte de la fonction pulmonaire après la circulation extracorporelle, les précautions efficaces et le traitement idéal touchant ce problème font toujours l'objet de débats. Nous voulions évaluer les effets d'une ventilation en pression positive continue (CPAP pour "continuous positive airway pressure») pendant la circulation extracorporelle sur les variables respiratoires et hémodynamiques.

Méthode : Dans notre étude randomisée, prospective et contrôlée, 120 hommes de 45 à 70 ans devant subir un premier pontage électif, ont reçu soit $10 \mathrm{~cm} \mathrm{H}_{2} \mathrm{O}$ de CPAP (Groupe $I$; $n=$ 60) pendant la circulation extracorporelle, soit ont servi de témoins (Groupe II ; $n=60$ ) et les poumons ont été ventilés à la pression atmosphérique pendant le pontage.

Résultats : La différence alvéolaire-artérielle de pression partielle en oxygène et la fraction de shunt ont été significativement plus élevées chez les témoins que chez les patients sous CPAP après la circulation extracorporelle $\left(T_{2}\right)$ et après la fermeture du sternum $\left(T_{3}\right),(P<0,05)$. Les variables hémodynamiques ont toujours été similaires dans les deux groupes. Dans les deux groupes aussi, les variables de la fonction pulmonaire postopératoire étaient plus basses que les valeurs de départ.

Conclusion : La ventilation à pression positive continue pendant la circulation extracorporelle a réduit la fraction de shunt et la différence alvéolaire-artérielle de pression partielle en oxygène pendant l'opération, mais n'a pas eu d'effet postopératoire prolongé sur chacune des variables. Donc, chez les patients dont la fonction pulmonaire préopératoire est normale, une CPAP de $10 \mathrm{~cm} \mathrm{H}_{2} \mathrm{O}$ n’améliore pas la fonction pulmonaire après la cardiochirurgie.

From the Department of Anesthesiology and Reanimation, ${ }^{*}$ and the Department of Thoracic and Cardiovascular Surgery, $†$ Dr. Siyami Ersek Thoracic and Cardiovascular Surgery Center, Ïstanbul, Turkey.

Address correspondence to: Dr. Pelin Karaca, Postane Mah. Rauf Orbay Cad. Bilginoglu Sitesi, NO: 3 Tuzla / Istanbul, Turkey. Phone:

+90-262-6785090; Fax: +90-262-6540055; E-mail: pelus72@yahoo.com

Accepted for publication May 1, 2005.

Revision accepted April 10, 2006.

Final revision accepted April 20, 2006.

Competing interests: None declared. 


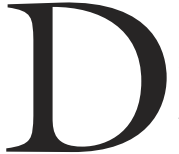
ESPITE improvements in cardiopulmonary bypass (CPB) techniques and postoperative intensive care, impaired pulmonary function is a well-documented complication of CPB, resulting in increased morbidity and mortality. The complication of 'postbypass lung' occurs with an incidence from $2 \%-64 \%$ of cardiac surgeries involving $\mathrm{CPB},{ }^{1,2}$ and is characterized by an increased alveolar-arterial oxygen partial pressure difference $\left(\mathrm{P}_{(\mathrm{A}-\mathrm{a})} \mathrm{DO}_{2}\right)$, atelectasis, and increased extravascular lung water (EVLW). ${ }^{3,4}$ Absent or reduced blood flow through the lungs during CPB, surgical trauma, intravascular microaggregates, and leucocyte activation are the main causes of 'postbypass lung'.

Several strategies have been evaluated to reduce the incidence and severity of pulmonary dysfunction seen following CPB including repeated vital capacity maneuvers, intermittent ventilation, and continuous airway pressure (CPAP) during $\mathrm{CPB}$. Although in some reports the use of CPAP during CPB was found to improve pulmonary function, the ideal management for the non-functioning lung during $\mathrm{CPB}$ remains controversial. ${ }^{4,5}$

The aim of this study was to determine whether CPAP at $10 \mathrm{~cm} \mathrm{H}_{2} \mathrm{O}$ during $\mathrm{CPB}$, would decrease intrapulmonary shunt fraction and improve postoperative pulmonary function in patients undergoing elective coronary artery bypass graft surgery.

\section{Methods}

After the study protocol had been approved by the local Ethics Committee, written informed consent was obtained from 120 ASA physical status II-III male patients, aged 45 to $70 \mathrm{yr}$ undergoing elective coronary artery bypass graft surgery. Included were patients with preserved left ventricular function (ejection fraction > $40 \%$ ), and with normal preoperative respiratory function [forced vital capacity (FVC ) > 60\% of predicted, and forced expiratory volume at one second $\left(\mathrm{FEV}_{\mathrm{l}}\right) /$ FVC > 60\%]. Patients with valvular disease or a history of chronic obstructive lung disease were excluded.

Premedication consisted of diazepam $0.15 \mathrm{mg} \cdot \mathrm{kg}^{-1}$ po the evening prior to surgery and midazolam 0.07 $\mathrm{mg} \cdot \mathrm{kg}^{-1} \mathrm{im}$ and scopolamine $0.01 \mathrm{mg} \cdot \mathrm{kg}^{-1} \mathrm{im}$ one hour preoperatively. A pulmonary artery catheter was inserted into the right internal jugular vein of all patients to evaluate hemodynamics. In addition, continuous electrocardiography, invasive blood pressure (radial artery, non-dominant side), end-tidal carbon dioxide and oxyhemoglobin saturation were monitored throughout surgery. Anesthesia was induced with fentanyl $20 \mu \mathrm{g} \cdot \mathrm{kg}^{-1}$ iv and propofol $2 \mathrm{mg} \cdot \mathrm{kg}^{-1} i$. Muscle relaxation was provided with pancuronium 0.1 $\mathrm{mg} \cdot \mathrm{kg}^{-1} i \mathcal{~}$. Anesthesia was maintained with fentanyl 0.3-1.0 $\mu \mathrm{g} \cdot \mathrm{kg}^{-1} \cdot \mathrm{min}^{-1}$, propofol $1 \mathrm{mg} \cdot \mathrm{kg}^{-1} \cdot \mathrm{hr}^{-1}$, and isoflurane (0.4-1.0\% end-tidal concentration) until initiation of CPB. During CPB, fentanyl was infused at $0.1 \mu \mathrm{g} \cdot \mathrm{kg}^{-1} \cdot \mathrm{min}^{-1}$, and propofol was infused at 0.5 $\mathrm{mg} \cdot \mathrm{kg}^{-1} \cdot \mathrm{hr}^{-1}$. After completion of CPB, fentanyl and propofol infusions were increased to individualized pre-bypass rates. Intermittent positive pressure ventilation with $10 \mathrm{~mL} \cdot \mathrm{kg}^{-1}$ tidal volume at $12 \mathrm{breaths} \cdot \mathrm{min}^{-1}$, and $100 \%$ oxygen $\left(\mathrm{F}_{\mathrm{I}} \mathrm{O}_{2}=1.0\right)$ was administered before and after completion of CPB. Vasodilators were not administered during any part of the study.

After initiation of $\mathrm{CPB}$, mechanical ventilation was discontinued in all patients. In Group I (CPAP group; $n=60$ ) lung inflation was maintained by delivery of an oxygen-air mixture administered at $2 \mathrm{~L} \cdot \mathrm{min}^{-1}$ $\left(\mathrm{F}_{\mathrm{I}} \mathrm{O}_{2}: 0.25\right)$ with CPAP. Continuous pulmonary airway pressure was established via a circle system with airway pressure maintained at $10 \mathrm{~cm} \mathrm{H}_{2} \mathrm{O}$ by adjusting the ventilator pop-off valve. The actual pressure in the circuit was monitored with an external manometer. In Group II (control group; $n=60$ ) the ventilator was disconnected from the breathing circuit, and the patient's lungs were vented to atmosphere.

Cardiopulmonary bypass was performed using a roller pump (Sarns 9000, Ann Arbor, MI, USA) and membrane oxygenator (Jostra Quadrox +VHK 4200, Hirrlingen, Germany). Priming was performed with $1500 \mathrm{~mL}$ Ringer's solution, $1 \mathrm{mg} \cdot \mathrm{kg}^{-1}$ heparin, $2 \times$ $10^{6}$ kallikrein inactivation units (KIU) aprotinin, 150 $\mathrm{mL}$ mannitol, $50 \mathrm{mEq} \mathrm{NaHCO}_{3}$. Non pulsatile-flow $2.4 \mathrm{~L} \cdot \mathrm{min}^{-1} \cdot \mathrm{m}^{2}$ and mild hypothermia (rectal temperature of $28^{\circ} \mathrm{C}$ ) were maintained. During cardiac arrest antegrade and retrograde administration of cold $\left(4^{\circ} \mathrm{C}\right)$ hyperkalemic $\left(20 \mathrm{mEq} \cdot \mathrm{L}^{-1}\right)$ blood cardioplegia was administered. Anticoagulation was achieved with bovine heparin (400 IU. $\mathrm{kg}^{-1}$ ) and monitored to achieve activated clotting time (ACT) levels of 480 sec. At the end of CPB heparin was neutralized with $1.3 \mathrm{mg}$ of protamine for every $100 \mathrm{U}$ of total heparin dosage. Additional protamine was administered to restore ACT to pre-bypass levels when necessary. All procedures were performed by the same surgeon using the same technique for myocardial protection and coronary revascularization. Proximal anastomoses were performed after aortic cross clamp release during the revascularization period. The criteria for separation from $\mathrm{CPB}$ were as follows: core body temperature of $37^{\circ} \mathrm{C}$, stable rhythm (preferentially sinus) with adequate heart rate, and acceptable arterial blood gas values $\mathrm{pH}>7.30, \mathrm{~K}<5.5 \mathrm{mEq} \cdot \mathrm{L}^{-1}$, hematocrit $>25 \%$.

All patients were managed in the surgical intensive care unit (SICU) postoperatively and mechanical ven- 
tilation was continued until the following conditions were present for at least two hours: 1 ) adequate level of consciousness, 2) tidal volume $\left(\mathrm{V}_{\mathrm{T}}\right)>5 \mathrm{~mL} \cdot \mathrm{kg}^{-1}$, 3) respiratory rate $<25$ breaths $\left.\mathrm{min}^{-1}, 4\right)$ arterial $\mathrm{pH}$ $>7.30,5)$ an arterial partial pressure of oxygen $\left(\mathrm{P}_{\mathrm{a}} \mathrm{O}_{2}\right)$ $>80 \mathrm{mmHg}$ with $\left.\mathrm{F}_{1} \mathrm{O}_{2}=0.4,6\right)$ an arterial partial pressure of carbon dioxide $\left.\left(\mathrm{P}_{\mathrm{a}} \mathrm{CO}_{2}\right)<45 \mathrm{mmHg}, 7\right)$ hemodynamic stability, and 8 ) chest tube drainage < $50 \mathrm{~mL} \cdot \mathrm{hr} \mathrm{r}^{-1}$.

Arterial and mixed venous blood gas analysis and hemodynamic measurements were performed at the following times:

$\mathrm{T}_{0}$ : Before induction of anesthesia, on room air,

$\mathrm{T}_{1}$ : After induction of anesthesia immediately before surgical incision at $\mathrm{F}_{\mathrm{I}} \mathrm{O}_{2}=1.0$,

$\mathrm{T}_{2}: 20$ min after termination of $\mathrm{CPB}$ at $\mathrm{F}_{\mathrm{I}} \mathrm{O}_{2}=1.0$,

$\mathrm{T}_{3}$ : Immediately after closure of sternum at $\mathrm{F}_{\mathrm{I}} \mathrm{O}_{2}=1.0$,

$\mathrm{T}_{4}$ : Postoperative fourth hour in the SICU at $\mathrm{F}_{\mathrm{I}} \mathrm{O}_{2}=0.4$, and

$\mathrm{T}_{5}$ : After tracheal extubation, when breathing nasal oxygen $\left(2 \mathrm{~L} \cdot \mathrm{min}^{-1}\right)$

Arterial and mixed venous blood-gas tensions were measured using the $\alpha$-stat method. The following hemodynamic variables were recorded: heart rate (HR), mean arterial pressure (MAP), mean pulmonary artery pressure, pulmonary capillary wedge pressure (PCWP), and central venous pressure. The following were calculated using standard formulae: cardiac index (CI), systemic vascular resistance index (SVRI), pulmonary vascular resistance index (PVRI), $\mathrm{P}_{(\mathrm{A}-\mathrm{a})} \mathrm{DO}_{2}$, and shunt fraction $\left(\mathrm{Q}_{\mathrm{S}} / \mathrm{Q}_{\mathrm{T}}\right)$.

All subjects underwent pulmonary function tests (PFT) before surgery and on the first, third, and fifth days following surgery using an automatic spirometer (Minato Autospiro AS-500, Minato Medical Science Co. Ltd., Osaka, Japan). Forced expiratory volume at one second, FVC, vital capacity (VC), maximal voluntary ventilation (MVV), forced expiratory flow between $25 \%$ and $75 \%$ of FVC [forced expiratory flow between $25 \%$ and $75 \%$ of FVC $\left.\left(\mathrm{FEF}_{25-75}\right)\right]$, and peak expiratory flow rate (PEFR) were recorded. Samples for arterial blood gas analysis were drawn at the time of each assessment of pulmonary function.

Sample size was calculated as follows: a $5 \%$ increase in shunt fraction was considered clinically significant with a standard deviation of 10. Fifty-nine patients in each group were required to achieve $80 \%$ statistical power with an $\alpha=0.05$. The SPSS (Statistical Package for Social Sciences for Windows version 10.0 Chicago, IL, USA ) was used for all statistical analyses. Data were compared using analysis of variance for repeated
TABLE I Patient characteristics and operative details

\begin{tabular}{lll}
\hline & $\begin{array}{l}\text { Group } I \\
(n=60)\end{array}$ & $\begin{array}{l}\text { Group II } \\
(n=60)\end{array}$ \\
\hline Age $(\mathrm{yr})$ & $57.8 \pm 8.6$ & $56.2 \pm 7.6$ \\
Height $(\mathrm{cm})$ & $176.7 \pm 6.7$ & $172.4 \pm 7.8$ \\
Weight $(\mathrm{kg})$ & $75.9 \pm 8.1$ & $73.6 \pm 8.6$ \\
BSA $\left(\mathrm{kg} \cdot \mathrm{m}^{-2}\right)$ & $1.9 \pm 0.1$ & $1.9 \pm 0.2$ \\
Hypertension $(n)$ & $15(75 \%)$ & $16(80 \%)$ \\
Diabetus mellitus $(n)$ & $8(40 \%)$ & $7(35 \%)$ \\
Smoker $(n)$ & $15(75 \%)$ & $16(80 \%)$ \\
Cross-clamp time $($ min $)$ & $63.8 \pm 26.4$ & $56.2 \pm 17.4$ \\
CPB time $($ min) & $99.6 \pm 28.2$ & $93.8 \pm 23.7$ \\
Duration of operation $($ min $)$ & $225.8 \pm 22.7$ & $231.5 \pm 16.2$ \\
Number of grafted vessels & $3.1 \pm 0.7$ & $3.0 \pm 0.7$ \\
Use of internal mammary & $19(95 \%)$ & $20(100 \%)$ \\
artery $(n)$ & & \\
Postoperative fluid & $+804.2 \pm 410.2$ & $+1035.7 \pm 403.08$ \\
balance $($ mL) & & \\
Length of hospital stay $($ days $)$ & $6.3 \pm 0.6$ & $6.3 \pm 0.7$ \\
Chest tube drainage & $817.5 \pm 79.4$ & $820.5 \pm 118$ \\
\hline Data are expressed as mean \pm SD. BSA = body surface area; CPB \\
= cardiopulmonary bypass.
\end{tabular}

measures (ANOVA) and the Mann-Whitney $U$ test was applied whenever ANOVA was significant. Within group comparisons were performed with one-way analysis of variance. Data are expressed as mean \pm SD. A $P$ value $<0.05$ was considered to indicate statistical significance.

\section{Results}

Groups were comparable with respect to demographic and intraoperative characteristics (Table I). There were no between-group differences with respect to HR, MAP, PCWP or CI (Table II). After induction of anesthesia SVRI decreased in both groups $(P<0.05)$, (Table III). Whereas PVRI was significantly higher at the fourth postoperative hour and after tracheal extubation compared to baseline $(P<0.05)$, MAP and PCWP remained unchanged in both groups.

The $\mathrm{P}_{(\mathrm{A}-\mathrm{a})} \mathrm{DO}_{2}$ and shunt fraction values are presented in Table IV. The $\mathrm{P}_{(\mathrm{A}-\mathrm{a})} \mathrm{DO}_{2}$ was greater in the control group compared with the CPAP group after CPB $\left(\mathrm{T}_{2}\right)$ and after closure of sternum $\left(\mathrm{T}_{3}\right),(P<$ $0.05)$. Shunt fraction was also greater in the control group compared with the CPAP group at corresponding measurement periods $(P<0.05)$. No differences were observed between groups with respect to $\mathrm{P}_{\mathrm{a}} \mathrm{O}_{2}$, $\mathrm{P}_{\mathrm{a}} \mathrm{CO}_{2}$ and $\mathrm{S}_{\mathrm{a}} \mathrm{O}_{2}$ values measured on first, third, and fifth postoperative days $(P>0.05)$, (Table V).

Preoperative and postoperative values for lung volumes and expiratory flow rates are presented in Table VI. Although VC, FEV 1, FVC, FEF $_{25-75}$, PEFR and 
TABLE II Hemodynamic variables

\begin{tabular}{llllllll}
\hline & Group & $T_{0}$ & $T_{1}$ & $T_{2}$ & $T_{3}$ & $T_{4}$ & $T_{5}$ \\
\hline HR $\left(\mathrm{min}^{-1}\right)$ & I & $73.4 \pm 22.4$ & $77.8 \pm 19.6$ & $75.5 \pm 21.7$ & $79.3 \pm 22.8$ & $74.9 \pm 24.5$ & $78.5 \pm 23.1$ \\
& II & $75.2 \pm 17.0$ & $79.7 \pm 19.3$ & $77.1 \pm 22.3$ & $78.2 \pm 18.2$ & $76.7 \pm 23.6$ & $79.2 \pm 28.4$ \\
$\mathrm{MAP}(\mathrm{mmHg})$ & I & $76.9 \pm 19.2$ & $74.6 \pm 16.3$ & $75.2 \pm 18.7$ & $78.2 \pm 21.6$ & $79 \pm 25.6$ & $79.9 \pm 27.3$ \\
& II & $77.4 \pm 22.5$ & $72.4 \pm 19.2$ & $76.3 \pm 21.2$ & $77.9 \pm 25.4$ & $78.6 \pm 29.1$ & $77.2 \pm 22.8$ \\
$\mathrm{MPAP}(\mathrm{mmHg})$ & I & $18.2 \pm 7.2$ & $17.9 \pm 9.6$ & $19.1 \pm 8.3$ & $20.2 \pm 9.8$ & $19.6 \pm 8.4$ & $20.0 \pm 6.7$ \\
& II & $18.3 \pm 8.3$ & $17.6 \pm 9.5$ & $17.9 \pm 9.1$ & $18.8 \pm 7.6$ & $20.1 \pm 8.6$ & $19.8 \pm 7.8$ \\
$\mathrm{CVP}(\mathrm{mmHg})$ & I & $7.7 \pm 4.8$ & $7.9 \pm 2.1$ & $8.2 \pm 4.9$ & $7.5 \pm 4.2$ & $7.9 \pm 4.8$ & $7.3 \pm 5.2$ \\
& II & $7.9 \pm 3.9$ & $7.2 \pm 3.1$ & $8.1 \pm 2.6$ & $7.3 \pm 5.4$ & $7.4 \pm 3.9$ & $8.2 \pm 3.1$ \\
$\mathrm{PCWP}(\mathrm{mmHg})$ & I & $9.8 \pm 6.2$ & $9.6 \pm 5.7$ & $10.3 \pm 4.1$ & $10.1 \pm 5.2$ & $9.4 \pm 5.1$ & $9.8 \pm 5.8$ \\
& II & $9.1 \pm 6.7$ & $8.8 \pm 6.2$ & $9.8 \pm 5.3$ & $9.0 \pm 5.4$ & $9.5 \pm 4.7$ & $9.6 \pm 5.5$ \\
$\mathrm{CI}\left(\mathrm{L} \cdot \mathrm{min}^{-1} \cdot \mathrm{m}^{-2}\right)$ & I & $4.1 \pm 0.9$ & $4.2 \pm 0.8$ & $3.9 \pm 0.7$ & $3.8 \pm 0.6$ & $4.0 \pm 0.8$ & $3.8 \pm 0.8$ \\
& II & $3.9 \pm 0.8$ & $4.0 \pm 0.6$ & $4.0 \pm 0.7$ & $3.9 \pm 0.7$ & $3.9 \pm 0.8$ & $3.9 \pm 0.7$ \\
\hline
\end{tabular}

Data are expressed as mean $\pm \mathrm{SD} . \mathrm{HR}=$ heart rate; $\mathrm{MAP}=$ mean arterial pressure; MPAP $=$ mean pulmonary artery pressure; $\mathrm{CI}=$ cardiac index; $\mathrm{CVP}=$ central venous pressure; $\mathrm{PCWP}=$ pulmonary capillary wedge pressure $(\mathrm{PCWP}$; units $\mathrm{mmHg})$. For abbreviations $\mathrm{T}_{0}$ to $\mathrm{T}_{5}$ refer to text.

TABLE III Systemic and pulmonary vascular resistance indices

\begin{tabular}{llllllll}
\hline & Group & $T_{0}$ & $T_{1}$ & $T_{2}$ & $T_{3}$ & $T_{4}$ & $T_{5}$ \\
\hline SVRI & I & $1532 \pm 472$ & $1278^{*} \pm 453$ & $1432 \pm 467$ & $1428 \pm 418$ & $1654 \pm 640$ & $1659 \pm 562$ \\
& II & $1602 \pm 536$ & $1329^{*} \pm 478$ & $1398 \pm 436$ & $1541 \pm 527$ & $1478 \pm 412$ & $1582 \pm 512$ \\
PVRI & I & $168 \pm 58$ & $157 \pm 68$ & $169 \pm 74$ & $171 \pm 72$ & $192^{*} \pm 69$ & $188^{*} \pm 54$ \\
& II & $164 \pm 65$ & $159 \pm 55$ & $174 \pm 69$ & $169 \pm 65$ & $189^{*} \pm 65$ & $191^{*} \pm 64$ \\
\hline
\end{tabular}

Data are expressed as mean \pm SD. PVRI $=$ pulmonary vascular resistance index $\left(\right.$ dyne $\left.\cdot \mathrm{sec}^{-1} \cdot \mathrm{m}^{-2} \cdot \mathrm{cm}^{-5}\right) ; \mathrm{SVRI}=$ systemic vascular resistance index $\left(\right.$ dyne $\left.\cdot \mathrm{sec}^{-1} \cdot \mathrm{m}^{-2} \cdot \mathrm{cm}^{-5}\right),{ }^{*} \mathrm{P}<0.05 \mathrm{vs}$ baseline. For abbreviations $\mathrm{T}_{0}$ to $\mathrm{T}_{5}$ refer to text.

TABLE IV Alveolar-arterial oxygen partial pressure differences and shunt fraction

\begin{tabular}{llllllll}
\hline & Group & $T_{0}$ & $T_{1}$ & $T_{2}$ & $T_{3}$ & $T_{4}$ & $T_{5}$ \\
\hline $\mathrm{P}_{(\mathrm{A}-\mathrm{a})} \mathrm{DO}_{2}(\mathrm{mmHg})$ & I & $19.8 \pm 11.4$ & $192.6 \pm 98.7$ & $223.4 \pm 46.5$ & $232.4 \pm 55.2$ & $96.3 \pm 36.2$ & $99.7 \pm 46.5$ \\
& II & $20.2 \pm 12.2$ & $202.5 \pm 96.7$ & $240.2^{*} \pm 58.4$ & $262.4^{*} \pm 50.6$ & $97.4 \pm 29.8$ & $96.7 \pm 42.8$ \\
$\mathrm{Q}_{\mathrm{S}} / \mathrm{Q}_{\mathrm{T}}(\%)$ & I & $13.5 \pm 5.0$ & $15.2 \pm 6.8$ & $18.8 \pm 8.9$ & $20.6 \pm 10.8$ & $6.8 \pm 4.8$ & $10.6 \pm 5.6$ \\
& II & $14.6 \pm 7.0$ & $16.3 \pm 8.4$ & $23.4^{*} \pm 11.2$ & $23.9^{*} \pm 11.2$ & $7.5 \pm 6.1$ & $9.8 \pm 6.1$ \\
\hline
\end{tabular}

Data are expressed as mean $\pm \mathrm{SD}$. Alveolar-arterial oxygen partial pressure difference $\left(\mathrm{P}_{(\mathrm{A}-\mathrm{a})} \mathrm{DO}_{2}\right)$ shunt fraction $\left(\mathrm{Q}_{\mathrm{S}} / \mathrm{Q}_{\mathrm{T}}\right) .{ }^{*} \mathrm{P}<0.05 v s$ Group I. For abbreviations $\mathrm{T}_{0}$ to $\mathrm{T}_{5}$ refer to text.

MVV decreased significantly $(P<0.05)$ after surgery compared to baseline values, there were no significant differences between groups at corresponding times $(P>0.05)$. Hyperinflation of the lungs due to added CPAP did not compromise surgical exposure in Group I patients. No patient experienced difficulty emerging from bypass or required inotropic support. All patients were discharged to the ward from the SICU on the first postoperative day. There were no perioperative myocardial infarcts or deaths.

\section{Discussion}

Cardiopulmonary bypass is well known to trigger an inflammatory process, and has adverse effects on endorgan function. The etiology of impaired pulmonary function after open heart surgery is multifactorial, including effects of the anesthetic technique, extracorporeal oxygenation technique, and metabolic changes. In particular, $\mathrm{CPB}$ activates leucocytes and inflammatory pathways, resulting in an alteration in capillary permeability. ${ }^{6-9}$ Activation of inflammatory pathways, such as the complement system and arachidonic acid metabolism, damage endothelial integrity and cause accumulation of interstitial fluid. ${ }^{10,11}$

Various techniques have been evaluated to decrease the incidence and severity of pulmonary impairment following $\mathrm{CPB}$. One measure is static inflation of the lungs (CPAP) during CPB. Loeckinger et al. ${ }^{5}$ showed that the amount of intrapulmonary shunt was significantly larger in a control group after thoracic closure and four hours after $\mathrm{CPB}$, whereas the magnitude of shunt in their CPAP $\left(10 \mathrm{~cm} \mathrm{H}_{2} \mathrm{O}\right)$ group remained 
TABLE V Arterial blood gas values

\begin{tabular}{|c|c|c|c|c|c|c|c|c|}
\hline & \multicolumn{2}{|l|}{ Preoperative } & \multicolumn{2}{|c|}{ Postoperative day 1} & \multicolumn{2}{|c|}{ Postoperative day 3} & \multicolumn{2}{|c|}{ Postoperative day 5} \\
\hline & Group I & Group II & Group I & Group II & Group I & Group II & Group I & Group II \\
\hline \multirow{3}{*}{$\begin{array}{l}\mathrm{P}_{\mathrm{a}} \mathrm{O}_{2} \\
(\mathrm{mmHg}) \\
\mathrm{maCO}_{2} \\
(\mathrm{mmHg}) \\
\mathrm{SaO}_{2} \mathrm{O}_{2} \\
(\%)\end{array}$} & $85.3 \pm 17.2$ & $88.6 \pm 16.9$ & $86.7 \pm 15$ & $84.8 \pm 17.6$ & $83.6 \pm 14$ & $84.2 \pm 17.8$ & $81.2 \pm 13.9$ & $82.8 \pm 14.2$ \\
\hline & $36.4 \pm 7.2$ & $35.8 \pm 6.3$ & $35.1 \pm 4.3$ & $35.8 \pm 4.2$ & $34.6 \pm 5.2$ & $34.9 \pm 5.0$ & $36.7 \pm 4.6$ & $36.3 \pm 5.1$ \\
\hline & $97.8 \pm 0.9$ & $97 \pm 1.0$ & $96.8 \pm 1.1$ & $96.7 \pm 1.2$ & $96.1 \pm 1.5$ & $96.3 \pm 1.3$ & $96.9 \pm 1.3$ & $96.4 \pm 1.1$ \\
\hline
\end{tabular}

Data are expressed as mean \pm SD.

TABLE VI Pre- and postoperative pulmonary function

\begin{tabular}{|c|c|c|c|c|c|c|c|c|}
\hline \multirow{2}{*}{ Group } & \multicolumn{2}{|l|}{ Preoperative } & \multicolumn{2}{|c|}{ Postoperative day 1} & \multicolumn{2}{|c|}{ Postoperative day 3} & \multicolumn{2}{|c|}{ Postoperative day 5} \\
\hline & $I$ & $I I$ & $I$ & $I I$ & $I$ & $I I$ & $I$ & $I I$ \\
\hline $\mathrm{VC}$ & & & & & & & & \\
\hline (L) & $3.1 \pm 0.8$ & $2.9 \pm 0.7$ & $1.2 * \pm 0.4$ & $1.1^{*} \pm 0.5$ & $1.4^{*} \pm 0.3$ & $1.4^{*} \pm 0.4$ & $1.8^{*} \pm 0.5$ & $1.7^{*} \pm 0.4$ \\
\hline $\begin{array}{l}\mathrm{FEV}_{1} \\
\left(\mathrm{~L} \cdot \mathrm{sec}^{-1}\right) \\
\mathrm{FVC}\end{array}$ & $2.4 \pm 0.6$ & $2.5 \pm 0.6$ & $1.2 * \pm 0.4$ & $1.1^{*} \pm 0.4$ & $1.3^{*} \pm 0.4$ & $1.2^{*} \pm 0.4$ & $1.4^{*} \pm 0.5$ & $1.4^{*} \pm 0.6$ \\
\hline$(\mathrm{L})$ & $2.7 \pm 0.7$ & $2.8 \pm 0.8$ & $1.1^{*} \pm 0.3$ & $1.2^{*} \pm 0.4$ & $1.4^{*} \pm 0.4$ & $1.3^{*} \pm 0.5$ & $1.7^{*} \pm 0.5$ & $1.8^{*} \pm 0.4$ \\
\hline $\begin{array}{l}\text { FEF25-75\% } \\
\left(\mathrm{L} \cdot \sec ^{-1}\right)\end{array}$ & $3.1 \pm 0.7$ & $3.0 \pm 0.9$ & $1.6^{*} \pm 0.6$ & $1.6^{*} \pm 0.6$ & $1.7^{*} \pm 0.6$ & $1.7^{*} \pm 0.5$ & $1.8^{*} \pm 0.8$ & $1.9^{*} \pm 0.8$ \\
\hline PEFR & & & & & & & & \\
\hline $\begin{array}{l}\left(\mathrm{L} \cdot \mathrm{sec}^{-1}\right) \\
\mathrm{MVV}\end{array}$ & $4.3 \pm 1.4$ & $4.2 \pm 1.7$ & $2.4^{*} \pm 1.0$ & $2.5^{*} \pm 0.9$ & $2.7^{*} \pm 0.8$ & $2.8^{*} \pm 0.7$ & $3.4^{*} \pm 1.1$ & $3.2^{*} \pm 1.0$ \\
\hline$\left(\mathrm{L} \cdot \mathrm{min}^{-1}\right)$ & $68.8 \pm 18.8$ & $68.2 \pm 19.1$ & $42.4^{*} \pm 17.7$ & $45.2^{*} \pm 18.1$ & $45.9^{*} \pm 18.1$ & $47.1^{*} \pm 15.5$ & $50.6^{*} \pm 15$ & $52.3^{*} \pm 14.8$ \\
\hline
\end{tabular}

Data are expressed as mean $\pm \mathrm{SD} .{ }^{*} P<0.05$ vs baseline. $\mathrm{VC}=$ vital capacity; $\mathrm{FEV}_{1}=$ forced expiratory volume in first second; $\mathrm{FVC}=$ forced vital capacity; FEF $25-75 \%=$ forced expiratory flow between $25 \%$ and $75 \%$ of FVC; PEFR = peak expiratory flow rate; MVV $=$ maximal voluntary ventilation.

unchanged. ${ }^{5}$ Ishikawa also reported that positive endexpiratory pressure (PEEP) with a pressure of $5 \mathrm{~cm}$ $\mathrm{H}_{2} \mathrm{O}$ initiated immediately after pleurotomy, prevents oxygen impairment and atelectasis after extracorporeal circulation. ${ }^{12}$ However, the duration of the positive effects of PEEP was not documented in that study.

In the current investigation, we examined the effects of CPAP at $10 \mathrm{~cm} \mathrm{H}_{2} \mathrm{O}$ on gas exchange and respiratory parameters during and after cardiac surgery. Although we found a lower shunt fraction and $\mathrm{P}_{(\mathrm{A}-\mathrm{a})} \mathrm{DO}_{2}$ in the CPAP Group I at $\mathrm{T}_{2}(20 \mathrm{~min}$ after the termination of $\mathrm{CPB}$ ) and $\mathrm{T}_{3}$ (after thoracic closure), like Loeckinger and Ishikawa, the difference between groups did not extend to the postoperative period. In this respect our results are similar to those of Berry et al. ${ }^{4}$ who reported significantly lower $\mathrm{P}_{(\mathrm{A} \text { - }}$ a) $\mathrm{DO}_{2}$ values in patients receiving $5 \mathrm{~cm} \mathrm{H}_{2} \mathrm{O} C P A P$ at $30 \mathrm{~min}$ after $\mathrm{CPB}$, but not at four hours and eight hours after $\mathrm{CPB}$.

Although many studies have evaluated the use of CPAP to minimize pulmonary dysfunction after $\mathrm{CPB}$, the results are conflicting. The technique was reported as an effective treatment in some studies, ${ }^{5,12,13}$ however others reported either no difference, or a short-lived difference between patients who received CPAP and those who did not. ${ }^{4,14,15}$ In addition, there is no consensus regarding the optimal level of CPAP. Magnusson et al. ${ }^{14}$ reported that CPAP with $5 \mathrm{~cm} \mathrm{H}_{2} \mathrm{O}$ applied during $\mathrm{CPB}$ did not prevent postoperative atelectasis and gas exchange impairment in pigs. Moreover, the maneuver was associated with a decrease in cardiac output compared to baseline. ${ }^{14}$ Boldt et al., ${ }^{3}$ on the other hand, reported that EVLW and $\mathrm{Q}_{S} / \mathrm{Q}_{\mathrm{T}}$ increased after bypass regardless of the CPAP pressure, and changes in $\mathrm{P}_{\mathrm{a}} \mathrm{O}_{2}$ correlated significantly with changes in EVLW. These investigators showed that static inflation with a moderate level of PEEP $\left(5 \mathrm{~cm} \mathrm{H}_{2} \mathrm{O}\right)$ at an $\mathrm{F}_{\mathrm{I}} \mathrm{O}_{2}$ of 0.21 decreased EVLW and improved $\mathrm{P}_{\mathrm{a}} \mathrm{O}_{2}$. Taking these studies into consideration, we applied a CPAP level of $10 \mathrm{~cm} \mathrm{H}_{2} \mathrm{O}$ in the present study. Magnusson et al. ${ }^{13}$ demonstrated that a vital capacity maneuver (inflating the lungs to $40 \mathrm{~cm} \mathrm{H}_{2} \mathrm{O}$ before termination of $\mathrm{CPB}$ ) is effective in preventing post- $\mathrm{CPB}$ atelectasis and gas-exchange 
impairment. Furthermore, they also showed that $\mathrm{P}_{\mathrm{a}} \mathrm{O}_{2}$, and shunt fraction are well correlated with atelectasis. ${ }^{16}$ It is now well-known that intrapulmonary shunt increases $20-25 \%$ after CPB. ${ }^{17,18}$ Westerdahl et al. ${ }^{19}$ reported that atelectasis persists up to the fourth postoperative day following cardiac surgery and deepbreathing exercises significantly decrease atelectasis.

Previous reports have shown significant deterioration in pulmonary function after CPB. Vargas et al. ${ }^{20}$ analyzed the relationship between pleural changes and PFT in patients who received saphenous vein graft (SVG group) alone or in combination with internal mammary artery (IMA group) grafting. These authors concluded that additional thoracic trauma in patients having IMA graft is associated with a larger decrement in pulmonary function. Shapira $e t ~ a l .{ }^{21}$ reported reductions of $19 \%-33 \%$ in all lung volumes, with the exception of residual volume and expiratory flow rates, which decreased from $33 \%$ to $37 \%$ in healthy males undergoing elective coronary artery bypass grafting. We also observed a significant decrease in PFT values after surgery, while hemodynamic variables remained similar in the control and CPAP groups.

In summary, CPAP administered during $\mathrm{CPB}$ decreases shunt fraction and alveolar-arterial oxygen partial pressure difference during surgery, but has no sustained effect on either variable postoperatively. We conclude that, in patients with normal preoprative pulmonary function, application of $10 \mathrm{~cm} \mathrm{H}_{2} \mathrm{O}$ CPAP does not improve lung function after cardiac surgery.

\section{References}

1 Fowler AA, Hamman RF, Good JT, et al. Adult respiratory distress syndrome: risk with common predispositions. Ann Intern Med 1983; 98: 593-7.

2 Andrejaitiene J, Sirvinkas E, Bolys R. The influence of cardiopulmonary bypass on respiratory dysfunction in early postoperative epriod. Medicina 2004; 40(Suppl 1): 7-12.

3 Boldt J, King D, Scheld HH, Hempellmann G. Lung management during cardiopulmonary bypass: influence on extravascular lung water. J Cardiothorac Anesth 1990; 4: 73-9.

4 Berry CB, Butler PJ, Myles PS. Lung management during cardiopulmonary bypass: is continuous positive airways pressure beneficial? Br J Anaesth 1993; 71: 864-8.

5 Loeckinger A, Kleinasser A, Lindner KH, Margreiter $J$, Keller $C$, Hoermann $C$. Continuous positive airway pressure at $10 \mathrm{~cm} \mathrm{H}_{2} 0$ during cardiopulmonary bypass improves postoperative gas exchange. Anesth Analg 2000; 91: 522-7.

6 Brasil LA, Gomes WJ, Salamao R, Buffolo E.
Inflammatory response after myocardial revascularization with or without cardiopulmonary bypass. Ann Thorac Surg 1998; 66: 56-9.

7 Anyanwu E, Dittrich H, Giesenking R, Enders HJ. Ultrastructural changes in the human lung following cardiopulmonary bypass. Basic Res Cardiol 1982; 77 : 309-22.

8 Parker DJ. Some changes in the lungs associated with cardiopulmonary bypass, In: Junod F (Ed.). Lung Metabolism. San Diego, CA: Academic; 1974: 459-79.

9 Menasche P, Edmunds LH Jr. The inflammatory response. In: Cohn LH, Edmunds LH (Eds). Cardiac Surgery in the Adult, 2nd ed. McGraw Hill; 2003: 349-60.

10 Hewson JR, Shaw M. Continuous airway pressure with oxygen minimizes the metabolic lesion of pump-lung. Can Anaesth Soc J 1983; 30: 37-47.

11 Pavelkova M, Kubala L, Ciz M, et al. Blood phagocyte activation during open heart surgery with cardiopulmonary bypass. Physiol Res 2005; 24 (Epub ahead of print).

12 Ishikawa S, Obtaki A, Takahashi T, et al. PEEP therapy for patients with pleurotomy during coronary artery bypass grafting. J Card Surg 2000; 15: 175-8.

13 Magnusson L, Zemgulis V, Tenling A, et al. Use of vital capacity maneuver to prevent atelectasis after cardiopulmonary bypass: an experimental study. Anesthesiology 1998; 88: 134-42.

14 Magnusson L, Zemgulis V, Wicky S, Tyden H, Hedenstierna $G$. Effect of CPAP during cardiopulmonary bypass on postoperative lung function. An experimental study. Acta Anaesthesiol Scand 1998; 42: 1133-8.

15 Stanley TH, Liu WS, Gentry S. Effects of ventilatory techniques during cardiopulmonary bypass on postbypass and postoperative pulmonary compliance and shunt. Anesthesiology 1977; 46: 391-5.

16 Magnusson L, Zemgulis V, Wicky S, Tyden H, Thelin S, Hedenstierna $G$. Atelectasis is a major cause of hypoxemia and shunt after cardiopulmonary bypass. An experimental study. Anesthesiology 1996; 87: 115363.

17 Lindberg H, Svennevig JL, Lilleaasen P, Vatne K. Pulsatile vs. non-pulsatile flow during cardiopulmonary bypass. A comparison of early postoperative changes. Scand J Thorac Cardiovasc Surg 1984; 18: 195-201.

18 Taggart DP, El Fiky M, Carter R, Bowman A, Wheatley $D J$. Respiratory dysfunction after uncomplicated cardiopulmonary bypass. Ann Thorac Surg 1993; 56: 1123-8.

19 Westerdahl E, Lindmark B, Eriksson T, Friberg Ö, Hedenstierna G, Tenling $A$. Deep-breathing exercises reduce atelectasis and improve pulmonary function 
after coronary artery bypass surgery. Chest $2005 ; 128$ : 3482-8.

20 Vargas F, Cukier A, Terra-Filho M, Hueb W, Teixeira $L R$, Light $R W$. Relationship between pleural changes after myocardial revascularization and pulmonary mechanics. Chest 1992; 102: 1333-6.

21 Shapira N, Zabatino SM, Abmed S, Murphy DM, Sullivan D, Lemole GM. Determinants of pulmonary function in patients undergoing coronary bypass operations. Ann Thorac Surg 1990; 50: 268-73. 